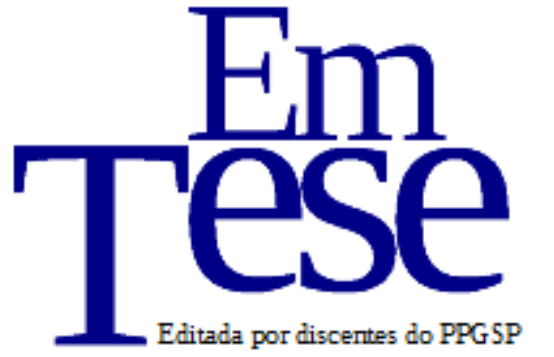

v. 15, n. 1 (parte II), p.170-188, mar./abr., 2018.

http://dx.doi.org/10.5007/1806-5023.2018v15n1p170

\title{
O Intelectocrata contemporâneo e a tênue passagem da luz à escuridão do poder ${ }^{1}$
}

\author{
Alexandre Augusto da Costa ${ }^{2}$ \\ Aline Andrade Pereira ${ }^{3}$ \\ Darlan Roberto dos Santos ${ }^{4}$
}

Resumo: Este artigo discute o papel do intelectual contemporâneo em tempos de convergência digital, a partir de um estudo de caso da personagem fictícia Dilma Bolada (criação de Jeferson Monteiro), que faz uma abordagem divertida da presidente Dilma Rousseff. Por meio da análise de conteúdo, buscou-se compreender, em momentos pontuais de grande repercussão, no primeiro e no segundo mandatos da presidente da República, se Monteiro comportou-se como um intelectocrata ou ideólogo (REIS FILHO, 2000). O primeiro conceito é atribuído ao intelectual que se coloca a serviço de um governo; e o segundo, diz respeito àquele que se mantém mais independente, ciente de suas convicções.

Palavras-chave: Comunicação Política; Intelectuais; Intelectocratas; Dilma Bolada.

\section{The contemporary intelectual and the tenuous passage from light to darkness of power}

Abstract: This article has the objective of investigate the role of the contemporary intellectual in convergence digital era, from a case study of the fictional character Dilma Bolada (created by Jeferson Monteiro), who makes a fun approach to President Dilma Rousseff. Through content analysis, it was sought to understand, in specific moments of great repercussion, in the first and second mandates of the president of the Republic, if Monteiro behaved as an intellecturat or ideologist (REIS FILHO, 2000). The first concept is attributed to the intellectual who puts himself at the service of a government; and the second concerns the one who is more independent, aware of his convictions.

Keywords: Political Communication; Intellectuals; Intellectocrats; Dilma Bolada.

\footnotetext{
1 (c) E EY Esta obra está licenciada com uma Licença Creative Commons Atribuição 4.0 Internacional.

${ }^{2}$ Mestre em Comunicação e Identidades - Comunicação e Poder - pela UFJF. E-mail: llexx@ hotmail.com.

${ }^{3}$ Bolsista do Programa Nacional de Pós-Doutorado (PNPD) Capes no PPGCOM-UFJF. Doutora em História, Mestre em Comunicação e Graduada em Jornalismo pela UFF. E-mail: alinexpe@ yahoo.com.br.

4 Pós-doutor em Literaturas Brasileiras pela PUC/MG. Doutor em Literatura Comparada pela UFMG. Professor da Faculdade Santa Rita (Fasar) e da Faculdade de Direito de Conselheiro Lafaiete (MG). E-mail: fenixdr@gmail.com.
} 


\section{Introdução}

O debate sobre o papel dos intelectuais no Brasil - da contestação do império ao período pós-Vargas (MICELI, 1979; COUTINHO, 2005) - ganhou, na contemporaneidade, novos elementos e um vasto caminho a ser explorado, como o advento da convergência digital, que promoveu uma profunda mudança na relação tempo-espaço e na própria cultura, influenciando na maneira como as pessoas, diariamente, consomem informações e divulgam conteúdos em áudio, vídeos e textos (JENKINS, 2008) ${ }^{5}$.

Embora não seja este o foco da análise pretendida, é importante contextualizar que, com a evolução dos meios de comunicação digital, surgiram novas e favoráveis condições para que os intelectuais se manifestem, não apenas mais em livros e nos tradicionais jornais e canais audiovisuais da imprensa, mas, também, em sites de notícias, blogs e redes sociais digitais (Facebook, Twitter, entre outros), estabelecendo-se uma maior liberdade de expressão, que, nas mídias tradicionais, muitas vezes entra em choque com o "filtro" exercido por um editor (gatekeeper). Porém, ao mesmo tempo em que estes meios forneceram condições de uma livre manifestação (intelligentsia) ${ }^{6}$, também evidenciam o papel dos intelectuais que estão a serviço do Estado (intelectocratas) ${ }^{7}$.

Nesta conjuntura, o objetivo deste artigo é, inicialmente, apresentar breve panorama sobre considerações acerca do intelectual na sociedade (como as do italiano Antonio Gramsci, do húngaro Karl Mannheim e do brasileiro Carlos Nelson Coutinho). Em seguida, fomentando o debate, empreenderemos análise sobre a atuação de Jeferson Monteiro, criador da página fictícia de humor "Dilma Bolada", no Facebook (https://www.facebook.com/DilmaBolada/?fref=ts) e no Twitter (https://twitter.com/diimabr?lang=pt), evidenciada através de suas postagens no Facebook, as quais foram levadas a público em momentos capitais dos dois mandatos de Dilma Rousseff, sendo: 1) 12 de junho de 2014: abertura da Copa do Mundo; 2) 26 de outubro de 2014: dia de votação do segundo turno das eleições presidenciais; e, 3 ) 2 de dezembro de 2015: a aceitação do processo de impeachment contra Dilma Rousseff pelo então presidente

\footnotetext{
${ }^{5} \mathrm{O}$ teórico Henri Jenkins argumenta que as transformações nas áreas da comunicação e da informática, nas últimas décadas, não se limitaram apenas a mudanças tecnológicas, mas provocaram alterações que influenciaram em uma cultura participativa das sociedades ocidentais, nas quais o consumidor também é provedor de conteúdo. Assim, classificou esse fenômeno como "cultura da convergência". Ver: JENKINS, 2008.

${ }^{6}$ De origem russa, este termo foi melhor esclarecido por Mannheim (1986) e consiste em uma certa classe flexível, provida de conhecimento filosófico e cultural, para esclarecer a sociedade sobre o conhecimento do mundo.

${ }^{7}$ Conceito que será abordado mais adiante neste artigo. Consiste na definição do intelectual que dispõe de suas habilidades para servir aos interesses de determinado governo. Ver: REIS FILHO, 2000.
} 
da Câmara e opositor Eduardo Cunha (PMDB). As categorias de análise por nós mobilizadas se baseiam na abordagem de Daniel Aarão Reis (2000) quando o historiador atualiza o pensamento de Bobbio (1997) e define o intelectual em: 1) intelectocrata (experto); e, ou, 2) ideólogo (intelligenti).

Trata-se de pesquisa bibliográfica, qualitativa e de um estudo de caso (GIL, 1999; YIN, 2013; GIBBS, 2009), no qual, para explorar os elementos da coleta de dados, utilizamos a análise de conteúdo, que, como defende Roesch (2009), tem por função classificar palavras ou frases, ou ainda categorias com o intuito de compreender o contexto em que se insere o objeto estudado. A hipótese lançada neste artigo é que Jeferson Monteiro exerce uma função mais propensa à de um intelectocrata (experto), do que a de um ideólogo (intelligenti).

\section{O papel do intelectual: algumas matizes teóricas}

\section{A função dos líderes culturais na sociedade}

O filósofo italiano Antonio Gramsci (2001) defendia que, à priori, qualquer um pode ser um intelectual; porém, nem todos exercem esta função social. Para Gramsci, isto se justifica porque qualquer homem, além de sua força de trabalho, desenvolve, de certa forma, alguma outra atividade que prioriza o intelecto.

\footnotetext{
Isto significa que, se se pode falar de intelectuais, é impossível falar de nãointelectuais, porque não existem não-intelectuais [...] Em suma, todo homem, fora de sua profissão, desenvolve uma atividade intelectual qualquer, ou seja, é um "filósofo", um artista, um homem de gosto, participa de uma concepção do mundo, possui uma linha consciente de conduta moral, contribui assim para manter ou para modificar uma concepção do mundo, isto é, para suscitar novas maneiras de pensar (GRAMSCI, 2001, p. 52)
}

De maneira didática, o filósofo estabelece duas categorias de intelectuais: tradicionais e orgânicos. Os primeiros, não necessariamente precisam ser ligados nativamente a um grupo, podem ser adeptos ou cooptados a partir do momento que frequentam o mesmo meio e defendem os mesmos valores e princípios. Estes, ainda, não se preocupam com a emancipação e maior alcance e distribuição da cultura, mas com a conservação de determinados valores institucionais, perpetuados geração após geração. Neste prisma encontram-se aqueles que têm uma forte identificação com determinada ideologia ou instituição, na defesa de seus interesses. Encaixam-se neste espectro, a aristocracia fundiária e os eclesiásticos, ligados, historicamente, às instituições tradicionais, em conflito com grupos rebeldes. Já os intelectuais orgânicos têm, como características, 
além de uma ligação direta a uma classe social de origem, o espírito dirigente, sendo portavozes dos interesses sociais, e almejam alcançar uma nova concepção de cultura e de igualdade de direitos. Esta categoria ainda se divide em intelectuais atuantes (os que desempenham estas funções) e não-atuantes (os que se abstêm). Na visão de Gramsci, toda transformação passa pela atuação dos intelectuais, que dirige a massa humana para se tornar independente. Desta forma,

[...] não existe organização sem intelectuais, isto é, sem organizadores e dirigentes, ou seja, sem que o aspecto teórico da ligação teoria-prática se distinga concretamente em um estrato de pessoas "especializadas" na elaboração conceitual e filosófica (GRAMSCI, 2001, p.104).

Gramsci acreditava que a atuação política, social e cultural das elites, detentoras do poder dominante, se encontrava estruturada na ideologia. Aos intelectuais representantes deste meio, cabia a tarefa de produzir e reproduzir os regimes de verdade desta ideologia, de modo a homogeneizar os valores culturais e sociais, naturalizando, assim, o domínio da burguesia. Por outro lado, aos intelectuais, provenientes das classes inferiores, caberia a tarefa de romper com a ordem vigente burguesa por meio da contestação, além de desenvolver as bases para uma nova ordem ideológica (revolução) pautada na ação (práxis).

Diante de mudanças históricas e sociais, o modelo de análise gramsciano passa a ser tomado como frágil, para análise do contexto nacional a partir da década de 1970, dada a configuração do Estado Nacional. Neste sentido, contribuições de outros pensadores fomentam o debate acerta do intelectual, engrossando o caldo teórico-crítico acerca do tema. É o caso do sociólogo húngaro Karl Mannheim (1986), que buscou aprimorar a sociologia do conhecimento $^{8}$, por meio da tese de um conhecimento socialmente enraizado (em um contexto sócio-histórico). Segundo o autor, os indivíduos guiam-se por pensamentos socialmente construídos, que embasam suas visões de mundo - seja de afirmação do atual contexto, ou ainda, de contestação à ordem vigente. Este movimento geraria um conhecimento social, que os cidadãos dividem entre si, nos grupos aos quais pertencem: “A principal tese da Sociologia do Conhecimento é que existem modos de pensamento que não podem ser compreendidos adequadamente enquanto se mantiverem obscuras suas origens sociais" (MANNHEIM, 1986, p. 30).

A tese de Mannheim visava desmistificar a ideologia marxista, que vinculava o trabalho intelectual às estruturas de dominação. Em vez disso, esta corrente teórica se

\footnotetext{
${ }^{8}$ Conceito desenvolvido, principalmente, a partir das obras de Thomas Kuhn, que consiste na defesa de que a epistemologia passa de uma visão normativa para a prática e não se mais se diferencia das demais ciências empíricas. Ver: BARNES, 1986.
} 
afirmava como um conhecimento pautado no contexto histórico-social para a ação, em um saber empírico. As mudanças históricas - principalmente, as relativas de classe - algumas vezes favoráveis a determinados grupos, e em outras desfavoráveis, não permitiram que os intelectuais na contemporaneidade fossem homogêneos (MANNHEIM, 1986). Desta forma, estes não estariam ligados a uma raiz comum, de classe, mas seriam "determinados, em seus pontos de vista, por este meio intelectual que contém todos os pontos de vista contraditórios" (MANNHEIM, 1986, p. 182).

Enquanto Mannheim apresenta uma perspectiva em que o intelectual flexível (que age por conveniência) pode emitir pareceres desvinculados de uma classe social - pois pertence a um extrato especial (intelligentsia); na visão gramsciana, qualquer pessoa pode ser um intelectual. Neste aspecto, Gramsci ${ }^{9}$, ainda se distancia de Mannheim, pois defende que um pensador não é completamente desprendido de uma classe, pois, ou é oriundo de alguma (orgânico), ou é cooptado e passa a ser um porta-voz, ou sacerdote de um grupo, como se fosse nativo (tradicional).

Outra abordagem clara sobre o papel dos intelectuais é a do sociólogo francês Pierre Bourdieu (2001). O pensador se distancia, em certa medida, da visão marxista, pautada na luta de classes e na dominação política, ao defender que a sociedade está inserida em uma grande estrutura, e as disputas se dão pelo poder simbólico. Para o sociólogo, a sociedade é composta através de campos sociais, que são estruturas que determinam as posições que os indivíduos ocupam nestes meios, para que se exerça plenamente o funcionamento e fortalecimento dos mesmos, em um exercício permanente de poder marcado pela disputa (BOURDIEU, 2001).

Os campos sociais, em sua estrutura, correspondem ao estado das forças entre os agentes ou instituições comprometidas na luta pela hegemonia. Para Bourdieu, trata-se de adquirir o monopólio da autoridade enquanto se concede o poder de transformar ou manter o capital específico destes espaços. Assim, a lógica específica dos campos sociais institui-se na forma de habitus, o que, para o autor, representa um haver - capital intelectual transferido aos integrantes dos campos como forma de operá-lo - e, ao mesmo tempo, objeto de disputa.

\footnotetext{
${ }^{9}$ Para o sociólogo francês Gérard Leclerc, a partir dos anos 1930, o pressuposto teórico de que a autoridade intelectual competia somente aos intelectuais orgânicos começou a ser questionado. Na visão de Leclerc (2004, p.56-57) os intelectuais são em grande número oriundos de classes mais abastadas, porém, ao consolidarem sua consciência ideológica podem renegar ou mesmo superar os valores de classe. Neste percurso podem se identificar, e até mesmo "representar" os interesses dos oprimidos, tidos como incapazes de perceberem a violência e a dominação a que são submetidos. Apesar de identificar este movimento, o teórico, porém não acredita nesta suposta pretensão dos intelectuais que se colocarem como porta-vozes dos mais pobres, já que isto consiste não somente em um problema político, mas principalmente sociológico.
} 
Um agente é parte integrante de uma instituição ou campo, à medida que produz ou sofre os efeitos dele (a) em seu corpo ou em sua mente. Obtém, assim, o capital simbólico (conhecimento acumulado historicamente), aquele que domina as melhores posições nestes campos ou que compõe maioria.

Esta relação de disputa pode, ainda, se configurar em uma violência simbólica, que consiste em uma dominação velada entre quem exerce poder e aquele que esta ação impõe seus efeitos. Os intelectuais, como dispõem de uma posição privilegiada nos campos político e cultural, têm um papel central neste processo de desnaturalização da violência simbólica (BOURDIEU, 2001).

Ao defender-se que um indivíduo ocupa determinada posição em um espaço físico e social, é possível imaginar uma aproximação entre Bourdieu e uma das teses de Mannheim (1986); a de que, para entender o papel de um intelectual, é preciso situá-lo no contexto histórico. Dizendo de outro modo: as considerações de Bourdieu estabelecem intercessões com a tese de Mannheim, no que se refere à importância ofertada ao posicionamento do intelectual - ideológico, social e histórico e até mesmo geográfico.

Podemos também estabelecer uma ligação com o pensamento de Gramsci, quando o filósofo italiano afirma que, à priori, todos são intelectuais. Em um sentido mais ramificado, Bourdieu (2001) também faz esta defesa, ao descrever que, nas disposições de um campo de conhecimento, pelo habitus, se formam vários tipos de conhecimento, especialidades que têm origem na prática. Quando Gramsci (2001) afirma que a transformação de uma realidade pelos intelectuais se dá pela práxis, no mesmo sentido, Bourdieu (2001), defende que os indivíduos buscam interferir na realidade do campo, buscando mudar a estrutura, pelo habitus.

\section{O intelectual e as relações com o poder político}

Em nossa análise, consideramos que um dos historiadores que mais compreenderam a história cultural brasileira e dos intelectuais é Carlos Nelson Coutinho (2005). O teórico defende que, no Brasil, as transformações sociais se deram, essencialmente pelo "Alto"10.

\footnotetext{
${ }^{10}$ Para Coutinho (2005), da Primeira República à Independência, surgiu a necessidade do Estado de montar um aparato cultural para que os intelectuais os servissem e orientassem as grandes massas "desorientadas". Surgiram as escolas de Direito, bem como os primeiros jornais, livros e peças teatrais. Na ditadura, isto se ampliou com a censura do Estado que criou o Departamento de Imprensa e Propaganda (DIP), como um aparelho cultural a serviço do governo. Este cenário se abriu apenas com o pós-ditadura em 1945 e o surgimento de diversas organizações culturais como jornais e revistas independentes ${ }^{10}$, aumento de editoras e a autonomia das recentes universidades criadas. Em 1964, com a aliança entre vários seguimentos das classes
} 
Uma conciliação entre as camadas populares com as elites. Enfatiza que as reformas e o processo de modernização econômico-social no Brasil seguiram uma "'via prussiana" (Lenin) ou uma "revolução passiva" (Gramsci), ambos acordos, sem uma revolução genuína, partindo das classes oprimidas.

Principalmente durante a ditadura pós-64, os intelectuais "elitistas" eram incentivados pelo Estado, enquanto os que se identificavam com a cultura popular foram isolados. Isso ocorreu devido ao escasso peso dos aparelhos privados de hegemonia (como conselhos, ONGs e mais diversidade na imprensa ${ }^{11}$ ) e a falta de partidos políticos de massa de expressão na formação social brasileira. Desta forma, eram condenados "os intelectuais que se recusavam à cooptação ao ostracismo, isolamento ou mesmo com profundas dificuldades de sobreviver (COUTINHO, 2005, p. 48). Os efeitos deste processo levaram a um desequilíbrio cultural na sociedade brasileira. Enquanto as classes dominantes encontravam com facilidade representantes que ecoaram suas demandas, as camadas populares eram decapitadas e tinham grande dificuldade para chegar a uma autoconsciência crítica (COUTINHO, 2005).

A esta cooptação, Coutinho (2005) denomina “intimismo à sombra do poder". Consiste no fato do intelectual, não necessariamente, defender as ideias do governo, mas manter uma postura neutra, que não coloque em questão a atual conjuntura. Desta forma, o pensador, protegido por esta sombra, "é livre para cultivar a própria " intimidade"” (COUTINHO, 2005, p. 49). O intelectual, assim, separado do povo, cultivava uma postura cosmopolita, elitista, distante da cultura nacional-popular.

Se levarmos a cabo o livre arbítrio do intelectual, como defendia Coutinho (2005, p.36), ao afirmar que a "liberdade de criação implica liberdade de crítica", como se configura o limite ético entre a missão e o compromisso com o público, se, às vezes o pensador está atrelado ao Estado? E quanto ao posicionamento político, seria considerado pelo povo como traição ou uma verdadeira missão do intelectual?

\footnotetext{
dominantes no golpe civil-militar, houve novo retrocesso. A nova ditadura impôs o fechamento de ferramentas importantes como os Centros Populares de Cultura (CPC) e o Instituto Superior de Estudos Brasileiros (ISEB), e fez intervenções nas universidades (COUTINHO, 2005).

${ }^{11}$ Em um contexto mais amplo, na discussão sobre a polêmica que toca a atuação dos intelectuais e a imprensa, a partir de interferências externas, como o capital, Leclerc (2004, p.87) afirma que, na falta de espaços tradicionais para se manifestarem, os intelectuais buscam, às vezes, adequarem-se à lógica midiática para se fazerem ouvidos. Este intelectual midiático, segundo o pensador francês, teria, ao longo do século XX, ocupado o espaço dos escritores. Sobre esta interface contraditória entre intelectuais e imprensa, ler Bourdieu (1991, p.663-664).
} 
Sobre a primeira indagação, de atrelamento ao Estado, cabe recorrermos ao conceito de intlectocrata ${ }^{12}$ utilizado pelo historiador Daniel Aarão Reis (2000), que se refere aos intelectuais com pouca bagagem escolástica, mas que colocam suas habilidades técnicas a serviço de um governo. Reis compara ${ }^{13}$ um conjunto de intelectuais com liberdade de crítica, como em Mannheim (1986), e aqueles que são orientados a se situarem à sombra do poder (COUTINHO, 2005).

Quanto à segunda pergunta, que se refere ao posicionamento político do intelectual, o italiano Norberto Bobbio (1997) ressalta a importância de esclarecer a distinção entre a política e a cultura. $\mathrm{Na}$ argumentação deste pensador, a política seria atribuição dos governantes, ao passo que a cultura estaria a cargo dos intelectuais. Se estes últimos têm como tarefa agitar ideias, levantar problemas, desatar os nós; aos políticos cabe a função de tomar decisões, de conviver com o contraditório em nome de uma governabilidade, podendo, até mesmo cortar os nós, em vez de tentar desatá-los. Entretanto, Bobbio pondera que, ao não se envolver, o homem da cultura pode ser taxado como inútil, estéril, professoral.

Outro ponto importante a se discutir, a partir do pensador italiano, é a divisão categórica que faz dos intelectuais ${ }^{14}$, sendo, “ideólogos [...] aqueles que fornecem princípios; e, por expertos, aqueles que fornecem conhecimentos meio" (BOBBIO, 1997, p. 73). Os primeiros teriam como função transmitir valores, ideias, concepções de mundo e elaborar os princípios para justificar uma determinada ação. Aos seguintes, caberia transmitir conhecimentos técnicos, de ordem prática, para resolver problemas, de forma que fujam à intuição política, e que suas ações sejam aceitas como racionais. Daniel Aarão Reis, ao analisar Bobbio, traz uma distinção entre a fronteira que separa "[...] ideólogos e expertos. Os primeiros [são] regidos pela ética das convicções (os intelligenti), os segundos, [...] das responsabilidades (os intelectocratas)" (REIS FILHO, 2000, p.13).

Ao se percorrer esta trajetória teórica, passamos à análise sobre a atuação de Jeferson Monteiro, através da página "Dilma Bolada", no Facebook e no Twitter. Conforme exposto

\footnotetext{
12 O termo tem origem no papel dos intelectuais russos de 1860 a 1880, a partir da modernização do estado, tomando o conceito de Gramsci sobre os estados orientais e ocidentais. O papel dos intelectocratas levou a uma série de reformas, como a abolição da servidão em 1861. Ver Reis Filho (2000).

${ }^{13} \mathrm{O}$ historiador desenvolveu sua crítica a partir das teorias de Gramsci, que dividiu os papéis dos intelectuais em orientais (nos regimes totalitários) e ocidentais (em economias abertas). Neste último âmbito, Reis utilizou duas variantes: intelligenti e intelectocratas. Ver Reis Filho (2000).

${ }^{14}$ Leclerc (2004, p.26) também abordou este tema, ao recorrer às pesquisas de Seymour M. Lipset e Asoke Basu (1976). Para o sociólogo francês, os intelectuais, por meio do repertório e da ideologia, teriam o poder de sincronizar os pensamentos dos indivíduos com a sociedade, engajando os mesmos para as pautas e dilemas que os afetariam. Já os experts teriam uma função mais técnica, ao sedimentarem saberes científicos para controlar a ação dos homens na sociedade.
} 
na introdução, pretende-se argumentar em defesa da hipótese que o jovem exerce uma função mais propensa à de um intelectocrata (experto), do que a de um ideólogo (intelligenti). Antes, porém, de se verificar tal pressuposto, é oportuno conhecer melhor como surgiu a relação comunicativa e política de Monteiro com a presidente Dilma Rousseff.

\section{Um aliado do governo que busca ser independente}

O avanço da internet, em meados de 1990 e nas décadas seguintes, trouxe mudanças significativas no trabalho dos intelectuais. Se, há alguns decênios, os pensadores utilizavam a imprensa escrita (GRAMSCI, 2001), atualmente, também fazem uso de outros canais, como as redes sociais digitais (Facebook e Twitter), com a possibilidade de criarem novos laços de relacionamento com o público (SANTAELLA e LEMOS, 2010). Neste universo de convergência cultural (JENKINS, 2008), se insere a personagem fictícia Dilma Bolada.

Criada em 2010 por Jeferson Monteiro, no Twitter, e, logo após, no Facebook ${ }^{15}$, a fan page ${ }^{16}$ faz uma sátira divertida da ex-presidente da República, o que adquiriu visibilidade durante a gestão da governante, e mesmo após seu afastamento do cargo. Como se fosse Dilma Rousseff, a personagem usa frases de deboche aos adversários e assume uma característica superlativa, ao se autodenominar "Diva, Rainha da Nação". O sucesso da fan page levou Dilma a convidar, em 2013, o autor da página fictícia para uma visita ao palácio do Planalto. Na ocasião, a presidente reativou suas contas oficiais no Twitter, Facebook e no Instagram $^{17}$. A personagem, que foi destaque mundial pela revista Forbes ${ }^{18}$ em 2014, se configurava, a partir de então como uma poderosa arma de apoio ao governo de Dilma Rousseff.

A lua de mel entre a personagem e a presidente, porém, ficou abalada logo após a Copa do Mundo do Brasil. Em meio à turbulenta campanha eleitoral, Jeferson Monteiro

\footnotetext{
15 Atualmente a página tem mais de 1,7 milhão de seguidores. Ver mais em $<$ www.facebook.com/dilmabolada>. Acesso em 23 mar. 2017.

${ }_{17}^{16}$ Página de fãs do Facebook para uso de instituições ou figuras públicas.

17 Disponível em: <http://www.cartacapital.com.br/blogs/midiatico/dilma-real-e-dilma-bolada-conversam-notwitter-7271.html>. Acesso em 23 mar. 2017.

${ }^{18}$ Em abril de 2014, a revista Forbes a elegeu como a personagem fictícia mais influente do mundo. A reportagem também destacou que Dilma Bolada teria um papel importante na manutenção positiva da imagem da presidente: "Para um político que continua a ser batido em pesquisas de popularidade e cujo governo está imerso em escândalos políticos, um admirador influente como Monteiro poderia gerar o tipo de propaganda política que a maioria dos políticos só podem sonhar”. (FORBES, edição eletrônica, 28 de abril de 2014). Disponível em: <http://www.forbes.com/sites/andersonantunes/2014/04/28/meet-dilma-bolada-facebooksmost-influential-fictional-character/>. Acesso em 23 mar. 2017.
} 
retirou ${ }^{19}$ a página do ar, alegando ser perseguido por alguns setores da oposição. Seis dias após o desligamento ser notícia, em jornais de todo o país, Monteiro voltou com a página e publicou: "Depois de mini-férias pós Copa, estou de volta melhor do que nunca, pronta para continuar reinando absoluta nas redes sociais e preparada para destruir as forças das trevas! ${ }^{20}$ ". Afora possíveis questões comerciais e financeiras, como as que envolvem captação de recursos e até mesmo supostos patrocínios, o episódio colocou em xeque, pela primeira vez, o compromisso ideológico do criador da fan page com o governo Dilma. A cooptação, desta vez, em vez de partir do Estado (GRAMSCI, 2001; COUTINHO, 2005), sairia da oposição.

Novo abalo atingiu a relação entre o criador da personagem e Dilma Rousseff, no dia 30 de setembro de 2015, quando, após a presidente anunciar a entrega de três ministérios ao PMDB (partido à época da base governista), o autor da fan page decidiu encerrar ${ }^{21}$ as atividades no Facebook ${ }^{22}$. A justificativa do desligamento de Monteiro, segundo a revista Época $^{23}$ do mês de agosto de 2015, porém, pode de ter sido outra. A reportagem informou que o autor da página fictícia tinha sido contratado pela agência de publicidade Pepper Interativa (contratada pelo PT), recebia uma renda de $\mathrm{R} \$ 20$ mil mensais, e que o rompimento se deu devido a não-renovação do contrato para 2016.

Menos de um mês depois, porém, a personagem retornou. No dia 21 de outubro de 2015, publicou uma postagem fazendo alusão ao filme "De Volta para o Futuro II", produção fictícia de 1989, em que os protagonistas - Marty McFly e o seu amigo o Dr. Brown - viajaram no tempo e chegaram ao futuro nesta mesma data ${ }^{24}$. Dilma Bolada publicou no Facebook um desenho ${ }^{25}$ com a presidente ocupando a máquina do tempo (automóvel americano DeLorian, adaptado na ficção), com a frase de título: "Viajou no tempo de 21/10/1975 para 21/10/2015" e a mensagem: "Porque às vezes é preciso que

\footnotetext{
19 Disponível em: <http://hashtag.blogfolha.uol.com.br/2014/07/23/dilma-bolada-sai-do-ar-no-facebook/>. Acesso em 19 mar. 2017.

${ }^{20}$ Disponível em: <http://g1.globo.com/politica/noticia/2014/07/perfil-de-dilma-bolada-volta-ao-ar-no-twittere-no-facebook.html>. Acesso em 23 mar. 2017.

21 Disponível em: <http://www1.folha.uol.com.br/poder/2015/09/1688490-dilma-bolada-rompeu-com-ogoverno-federal-diz-autor-de-parodia.shtml>. Acesso em 24 mar. 2017.

22 "Dilma não precisa do meu apoio no governo dela. Nem o meu e nem o de ninguém que votou nela. Afinal, para ela só importa o apoio do PMDB e de parte do empresariado para que ela se mantenha lá onde está. Trocou o governo pelo cargo" (JEFERSON MONTEIRO, em publicação no Facebook, 30 de setembro de 2015). Acesso em 24 mar. 2017.

23. Disponível em: <http://epoca.globo.com/tempo/noticia/2015/08/agencia-contratada-pelo-pt-paga-r-20-milde-salario-dilma-bolada.html>. Acesso em: 24 mar. 2017.

24 Disponível em: <http://g1.globo.com/pop-arte/cinema/noticia/2015/10/de-volta-para-o-futuro-saiba-comocelebrar-21102015-com-marty-mcfly.html>. Acesso em 24 mar. 2017.

25 Disponível em: <http://veja.abril.com.br/blog/radar-on-line/marketing/dilma-bolada-faz-versao-de-voltapara-o-futuro-de-dilma/>. Acesso em 24 mar. 2017.
} 
voltemos do passado para que sejamos coerentes com o nosso futuro!" (DILMA BOLADA, em publicação no Facebook, em 21 de outubro de 2015).

No segundo mandato, Dilma enfrentou dificuldades de governabilidade, que culminaram com o Impeachment, após denúncias de corrupção na Petrobras, oriundas da operação Lava Jato da Polícia Federal e do Ministério Público Federal, além da acusação de ter cometido crimes de responsabilidade fiscal, o que levou à decisão no Congresso Nacional. O que discutiremos a seguir é se Jeferson Monteiro, mesmo em uma relação conturbada com a presidente, se comportou em momentos decisivos no governo como um intelectocrata (experto) ou um ideólogo (intelligenti).

\section{Momentos capitais do governo Dilma: como agiu Jeferson Monteiro?}

No primeiro momento importante analisado neste artigo, que se refere à abertura da Copa do Mundo no Brasil (12 de junho de 2014), Jeferson Monteiro fez três postagens no Facebook $^{26}$. A primeira delas:

IMAGEM 1: “Arrasando” na abertura da Copa.

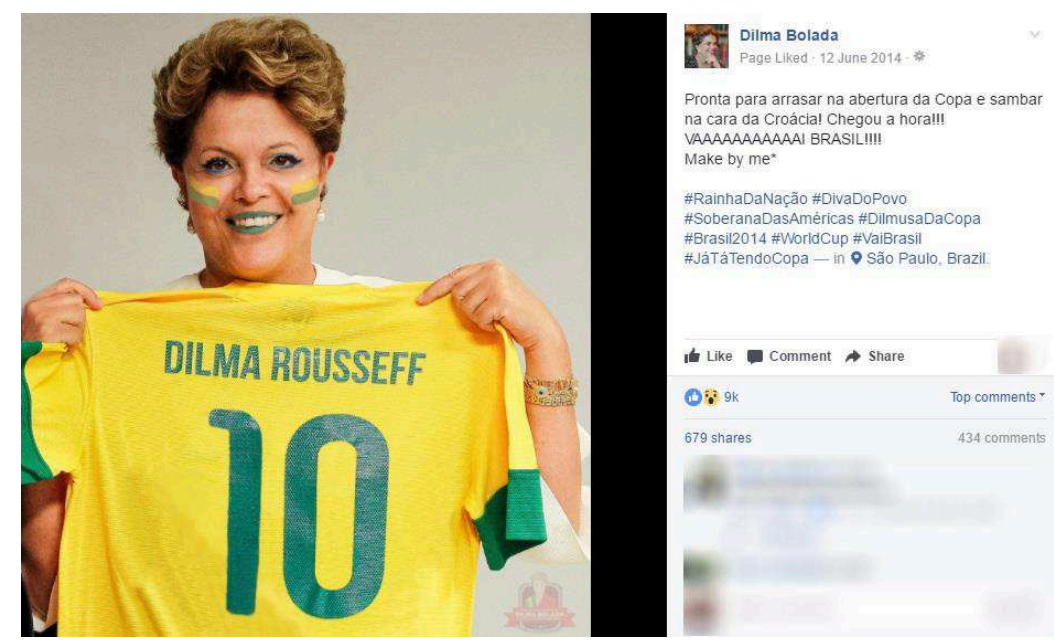

DILMA BOLADA em primeira postagem no Facebook, no 12 de junho de 2014.

A imagem traz, de maneira descontraída, uma provocação de Dilma Bolada ao time da Croácia, adversário da Seleção Brasileira, com a frase: "Pronta para arrasar na abertura da

\footnotetext{
${ }^{26}$ Cabe lembrar, que havia um clima de tensão à respeito de uma possível não realização do evento, com manchetes anunciando o caos que seriam os aeroportos e dos jogos em obras não acabadas Disponível em: $<$ http://veja.abril.com.br/blog/reinaldo/geral/copa-do-mundo-no-atual-ritmo-pais-estara-pronto-em-2038incompetencia-megalomania-roubalheira/>. Acesso em 24 mar. 2017.
} 
Copa e sambar na cara da Croácia! Chegou a hora!!! Vaaaaaaaai Brasil!!!! Make by me"’. Chamam atenção as hashtags ${ }^{27}$ que fazem uma identificação hiperbólica da presidente com o público, como “\#RainhaDaNação, \#DivaDoPovo, \#SoberanaDasAméricas, \#DilmusaDaCopa \#”.

A segunda publicação refere-se ao dia de abertura da Copa:

IMAGEM 2: Look do dia
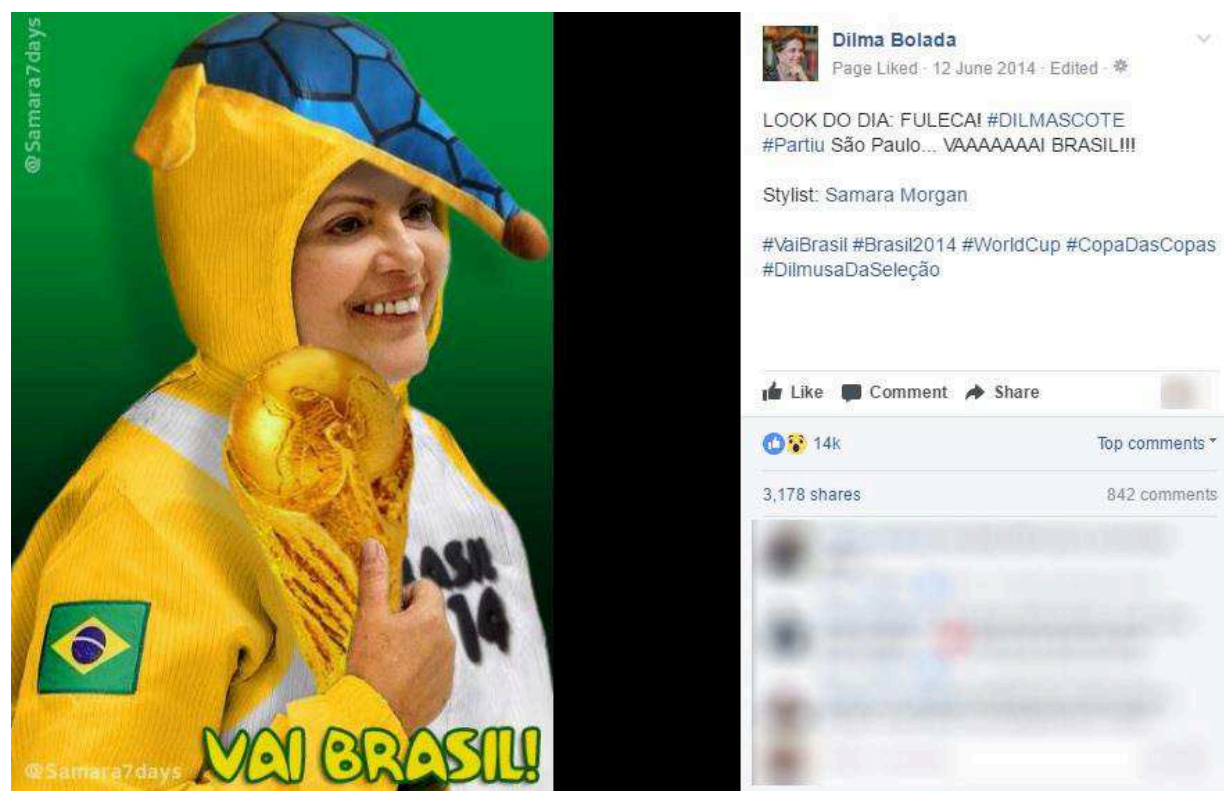

DILMA BOLADA em segunda postagem no Facebook, no 12 de junho de 2014.

Nessa postagem, Monteiro foi mais ousado. Explorou o humor grotesco (ridículo) e por meio de uma montagem com o rosto de Dilma, a colocou em uma roupa do mascote da competição, o Fuleco. Houve, ainda, uma terceira postagem no mesmo dia:

IMAGEM 3: Cerimônia de abertura da Copa

\footnotetext{
${ }^{27}$ Palavras-chave utilizadas nas redes sociais digitais para marcar ou definir um tema que é compartilhado e vêm acompanhadas do símbolo "\#”.
} 


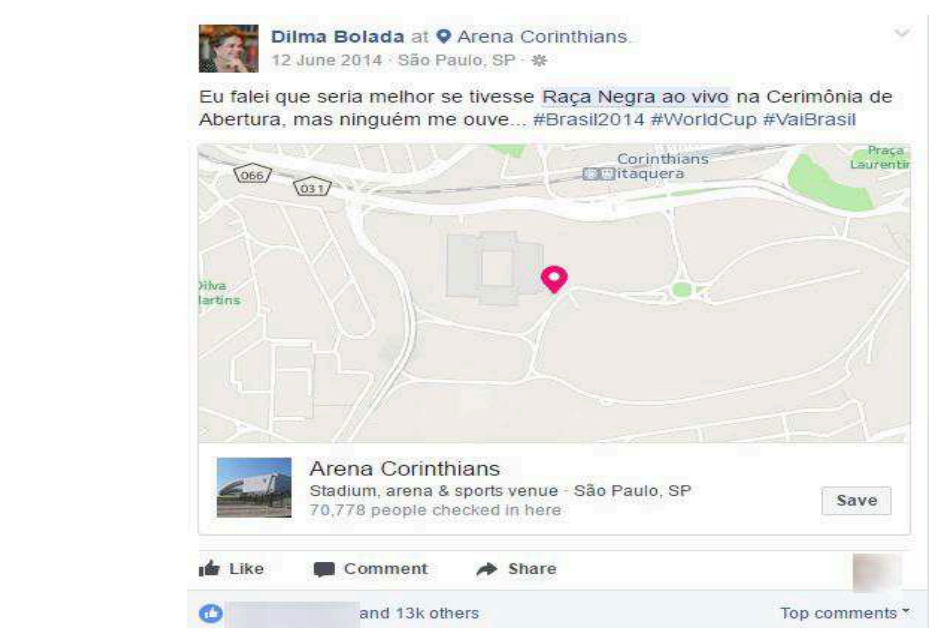

DILMA BOLADA em terceira postagem no Facebook, no 12 de junho de 2014.

Na imagem, Dilma Bolada faz uma ironia com a apresentação musical de abertura do evento, que colocou, no mesmo palco, Claudia Leite e os astros internacionais, Jennifer Lopez e Pitbull, cantando a música tema, "We Are One": "Eu falei que seria melhor se tivesse Raça Negra ao vivo na Cerimônia de Abertura, mas ninguem me ouve...”. O tom da crítica de Monteiro, que antecipou os editoriais negativos da imprensa nos dias seguintes, provavelmente se deu pela organização da Copa não ter dado oportunidade a outros cantores nacionais mais tradicionais, ou mesmo, de outros estilos musicais, como o samba.

O item 2 (dois) diz respeito à votação do segundo turno na eleição presidencial de 2014, quando Dilma foi reeleita. Em um clima tão acirrado, Dilma Bolada realizou postagens pontuais às vésperas do pleito, sendo uma em 24 de outubro e outra em 26 (dia da votação). No dia anterior à votação, 25, a personagem não fez nenhuma postagem no Facebook.

Dilma Rousseff realizou, no dia 24 de outubro, o último debate na televisão, antes da votação no domingo (26). De maneira divertida, momentos antes, Bolada publicou:

IMAGEM 4: Fazendo um lanchinho 


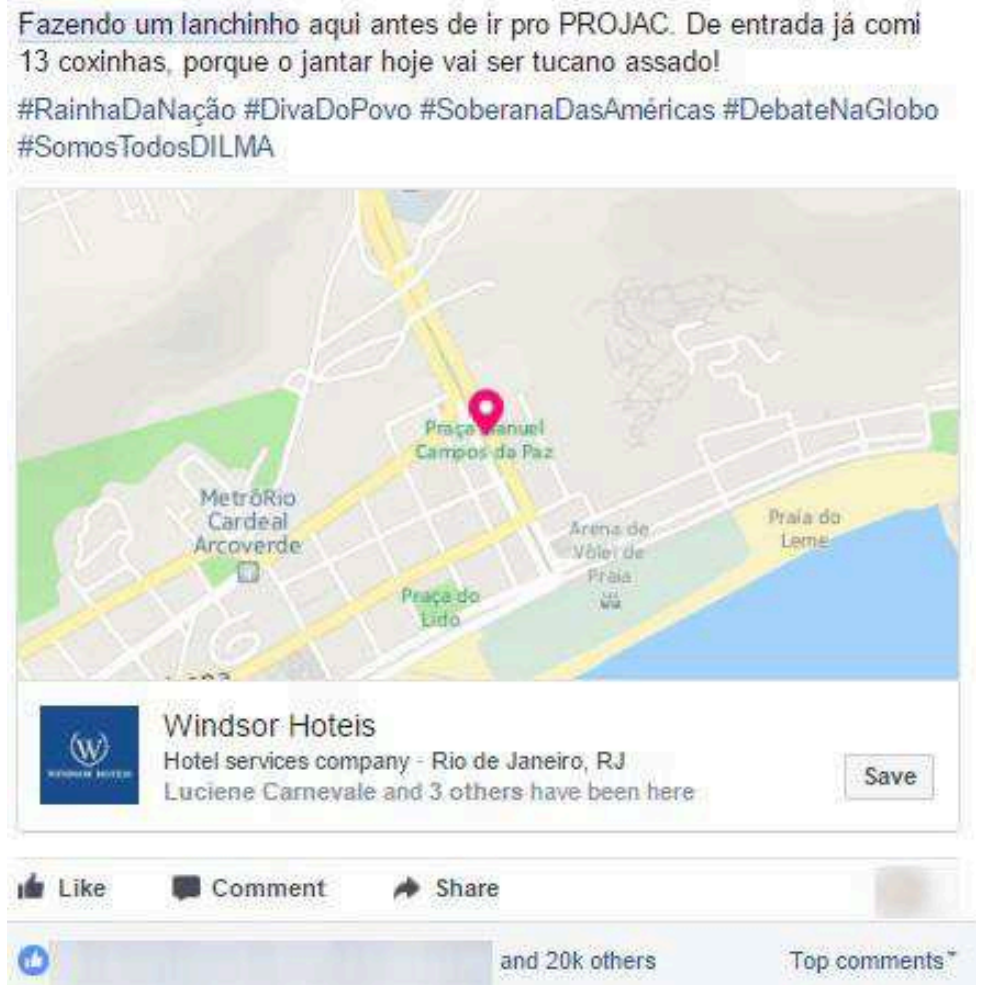

DILMA BOLADA em postagem no Facebook, em 24 de outubro de 2014.

Na imagem, a declaração: "Fazendo um lanchinho aqui antes de ir pro PROJAC. De entrada já comi 13 coxinhas, porque o jantar hoje vai ser tucano assado!". Foi uma provocação direta aos eleitores de Aécio Neves (adversário concorrente à presidência pelo PSDB), chamados de "coxinhas" pelos militantes da esquerda.

Já no dia da eleição, Dilma Bolada compartilhou uma publicação do Twitter de um internauta, que dizia que não era preciso amar o PT para votar em Dilma, e que apostar em Aécio seria como assumir não gostar do Brasil.

\section{IMAGEM 5: "Apenas verdades"}

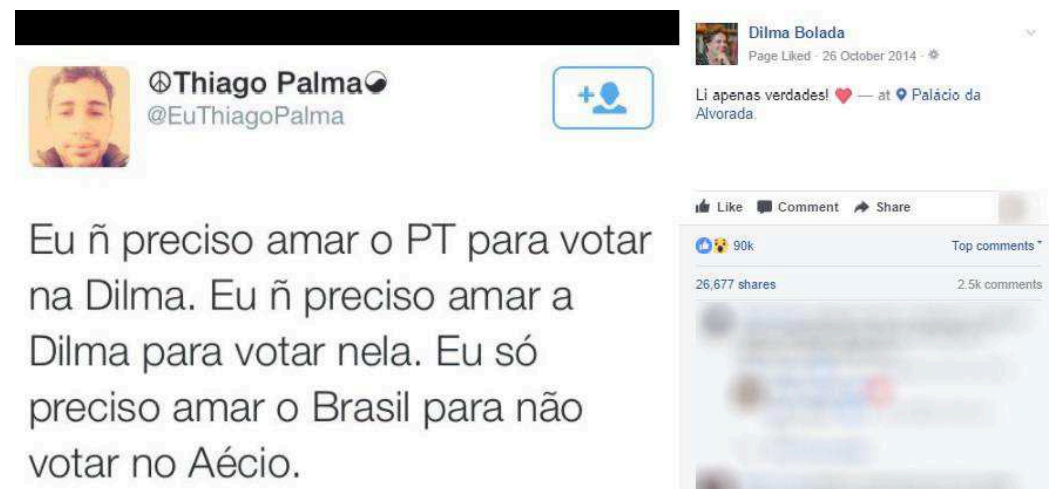

DILMA BOLADA em postagem no Facebook, em 26 de outubro de 2014. 
Pouco mais de um ano depois, quando a tensão se instalara definitivamente no governo Dilma, mais precisamente, no dia 02 de dezembro de 2015, data em que a denúncia de impeachment foi acatada na Câmara dos Deputados, Monteiro publicou uma imagem da presidente Dilma, mesclando a cabeça da presidente ao corpo da personagem principal do filme Jogos Vorazes: A esperança - o final ${ }^{28}$ e a frase, "Se me atacá, eu vou atacá" (BRASIL, Inês $)^{29}$, uma mescla, também, de referências pop.

IMAGEM 6: "Se me atacá, eu vou atacá"

\section{Dilma Bolada}

2. December 2015 at $18: 50-($ ) - * *

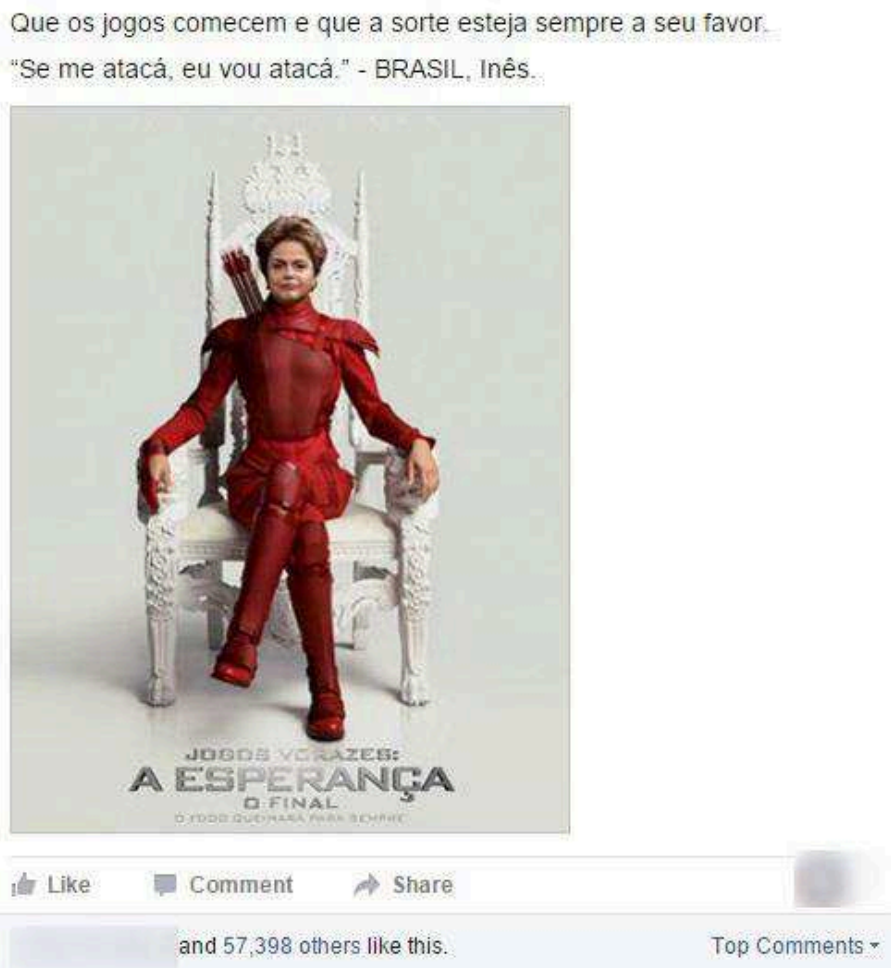

DILMA BOLADA em postagem no Facebook, em 2 de dezembro de 2015.

\footnotetext{
${ }^{28}$ Filme estrelado pela atriz Jennifer Lawrence interpretando a personagem Katniss Everdeen. O filme inspirado no mito grego de Teseu, narra a história de uma guerreira que trava uma luta contra o governo autoritário de Panem.

${ }^{29}$ Performer que ficou famosa pela divulgação de um vídeo quando foi candidata a integrante do Big Brother Brasil 13 na TV Globo. A candidata não conquistou a vaga, mas o vídeo se espalhou e fez sucesso na internet. Disponível em: <https://www.youtube.com/watch?v=3adl33jR6-s>. A frase em questão foi divulgada em outro vídeo, quando foi candidata ao BBB 14. Disponível em: <https://www.youtube.com/watch?v=tjbFI8qKEwU>. Acesso em 25 mar. 2017.
} 
Ao fazer esta montagem, Bolada tentou demonstrar que a presidente Dilma estaria disposta a continuar sua luta contra setores da oposição que queriam interromper seu mandato, por um processo de Impeachment.

Quanto às categorias de análise, é possível inferir que: 1) Há a hipótese (acatada, sob nossa análise), de que Jeferson Monteiro agiu não só como publicitário, mas, também, como um intelectocrata (experto) nas publicações em que mostrou claramente que estava servindo à presidente e forneceu aos internautas/eleitores os meios práticos de manifestarem sua adesão e aprovação às ações de Dilma (BOBBIO, 1997; REIS FILHO, 2000). Isto é evidente nas postagens (figuras 1 e 2), quando Dilma mostra a camisa da seleção Brasileira de Futebol, ou mesmo quando se "veste" de mascote da competição e utiliza hashtags como “\#CopaDasCopas, \#VaiBrasil” (até então, em xeque pela grande imprensa); e na imagem 5, ao replicar uma postagem do Twitter de um eleitor, que, mesmo não sendo tradicional eleitor do PT, optou por votar em Dilma, com o receio do adversário Aécio Neves vencer.

Em relação à hipótese de que Monteiro se comportou como um ideólogo (intelligenti), ao transmitir valores, ideias e concepções de mundo, ciente de suas responsabilidades e posições (BOBBIO, 1997; REIS FILHO, 2000), é possível considerar que houve esta conduta, expressa no dia 12 de junho (na figura 3), quando fez uma crítica aberta à cerimônia de abertura da Copa do Mundo; ainda, no dia 26 de outubro (figura 4), nas eleições presidenciais, ao ironizar e menosprezar os eleitores "coxinhas", partidários do PSDB; e ainda, em 2 de dezembro de 2015, quando o então presidente da Câmara, Eduardo Cunha, acatou o pedido de Impeachment contra Dilma. Nesta última postagem (figura 6), Monteiro mostrou que Dilma estava "pronta para guerra".

\section{Considerações finais}

Após apresentarmos algumas matizes teóricas, a respeito do papel dos intelectuais na sociedade contemporânea, reiteramos concordância com a colocação de Daniel Aarão Reis (2000, p. 11), de que eles não chegaram ao fim, mas "estão mais vivos do que nunca". À luz da realidade brasileira, de certo modo, este trabalho demonstrou que os intelectuais foram peças-chave nas reformas que ocorreram pelo "Alto", sempre em acordo com as elites dominantes (COUTINHO, 2005).

Nos momentos de conturbação social e política, ventilou-se que muitos intelectuais, ora estavam a serviço do regime - à sombra do poder (COUTINHO, 2005); ora, em outros períodos, mais independentes, à procura de estabelecer uma identidade nacional. Mais 
recentemente, após a redemocratização, ainda há intelectuais atuantes na cultura nacional, que se expressam nas artes diversas e nos meios de comunicação tradicional. Porém, com o advento da WEB 2.0, os canais de contato com o público se ampliaram, e deram voz aos intelectuais, até então, com acesso restrito (ou mais difícil) aos veículos de divulgação massiva, como a imprensa ou a televisão.

Neste contexto surge Jeferson Monteiro ${ }^{30}$, autor da página de humor Dilma Bolada. Um publicitário que, por meio de suas postagens no Facebook e no Twitter, ou mesmo no seu conturbado relacionamento com a presidente, trouxe implicações políticas positivas e algumas negativas ao governo Dilma Rousseff. A personagem criada por Monteiro nasceu, por assim dizer, independente; assim prosseguindo até alcançar o sucesso em 2013, quando começou a se aproximar da presidente e foi destaque na imprensa internacional, gozando de imenso prestígio e fornecendo meios para a defesa de ações do governo Dilma.

O cenário mudou, como foi relatado, no momento em que foi confrontado pela oposição e, ele, ao negar qualquer cooptação, passou a ser consultor da presidente. Porém, após atritos com Dilma, superados em 2015, em alguma medida, é possível concluir que Monteiro se expôs ao ponto de se esconder na sombra do governo, e caminhou para o isolamento. Como narrou brilhantemente Coutinho, ao relatar a realidade histórica brasileira: "os intelectuais que se recusavam à cooptação ao ostracismo, isolamento ou mesmo com profundas dificuldades de sobreviver" (COUTINHO, 2005, p.48).

Por fim, este artigo questiona: qual seria o caminho viável para o criador da página fictícia, que ainda permanece ativa? Provavelmente, sua postura deveria ser a de se empenhar, como vem fazendo, no papel de "intelectocrata", defendendo os ideais do governo Dilma e, após seu Impeachment, mantendo a tese de que a presidente foi vítima de um golpe. A saída pode estar na estratégia apresentada pela personagem nos primeiros anos em que surgiu: situar-se, nem tanto à luz, nem muito à sombra; mas na penumbra (meia luz) do poder.

\footnotetext{
${ }^{30}$ Sua biografia é mantida sob certo mistério, já que, diante da visibilidade que se pretendia dar à personagem, a persona de Jeferson parece ter sido mantida em segundo plano. Em suas redes sociais e em entrevistas, o jovem apenas se identifica como publicitário.
} 


\section{Referências}

BARNES, B. T.S. Kuhn e as Ciências Sociais. México: Fondo de Cultura Económica, 1986.

BOBBIO, N. Os intelectuais e o poder: dúvidas e opções dos homens de cultura na sociedade contemporânea. São Paulo: UNESP, 1997.

BOURDIEU, P. Campo intelectual e projeto criador. In.: POUILLON, Jean. et al. (Orgs). Problemas do estruturalismo. Rio de Janeiro: Zahar, 1968.

Fourth lecture. Universal corporatism: the role of intellectuals in the Modern world. Tradução: Gisele Sapiro e Brian McHale. In: Poetics Today. National Literatures/Social Spaces, Winter 1991, p. 655-669.

2010.

O poder simbólico. $13^{\mathrm{a}}$ ed. Tradução de Fernando Tomaz. Rio de Janeiro: Bertrand Brasil,

. Meditações pascalianas. Rio de Janeiro: Bertrand Brasil, 2001.

COUTINHO, C. N. Cultura e sociedade no Brasil. Ensaios sobre ideias e formas. Rio de Janeiro: DP\&A, 2005.

GIBBS, G. Análise de Dados Qualitativos. Porto Alegre: Artmed, 2009.

GIL, A. C. Métodos e Técnicas de Pesquisa Social. $6^{\text {a }}$ Ed. São Paulo: Atlas, 2008.

GRAMSCI, A. Cadernos do Cárcere: Os intelectuais. O princípio educativo Jornalismo. Vol. 2. Rio de Janeiro: Civilização Brasileira, 2001.

LECLERC, G. Sociologia dos intelectuais. Trad. Paulo Neves. São Leopoldo - RS. Unisinos, 2004.

MANNHEIM, K. Ideologia e utopia. Rio de Janeiro: Guanabara, 1986.

. Sociologia da Cultura. Coleção de Estudos. 2a ed. São Paulo: Perspectiva, 2001.

MICELI, S. Intelectuais e Classe Dirigente no Brasil (1920-1945). São Paulo: Difel, 1979.

REIS FILHO, D. A. (org). Intelectuais, história e política (séculos XIX e XX). Rio de Janeiro: Ed. 7 Letras, 2000.

ROESCH, S. M. A. Projetos de estágio e de pesquisa em administração: guia para estágios, trabalhos de conclusão, dissertações e estudos de caso. 3. ed. São Paulo: Ed. Atlas, 2009.

SANTAELLA, L.; LEMOS, R. Redes sociais digitais - A cognição conectiva do Twitter. São Paulo: Ed. Paulus, 2010.

YIN, R. K. Estudo de caso: planejamento métodos. Trad. Daniel Grassi. $3^{\text {a }}$ ed. Porto Alegre: Bookman, 2005.

Recebido em 26-03-2017;

Revisado em 12-6-2017;

Publicação em 04-05-2018. 